\title{
GROWTH MECHANISM AND FUNCTIONAL PROPERTIES OF GAS-PHASE SYNTHESIZED FEW-LAYER GRAPHENE
}

\author{
1'Ondřej JAŠEK, ' ${ }^{1} J o z e f$ TOMAN, ${ }^{1}$ Miroslav ŠNÍRER, ${ }^{1}$ Vít KUDRLE, ${ }^{1}$ Jana JURMANOVÁ, \\ ${ }^{1}$ Dalibor VŠIANSKÝ \\ ${ }^{1}$ Faculty of Science - Masaryk University, Brno, Czech Republic, EU, jasek@physics.muni.cz
}

https://doi.org/10.37904/nanocon.2021.4305

\begin{abstract}
Microwave plasma-based gas-phase synthesis of graphene and its derivatives represents a simple, environmentally friendly, and easily scalable production method enabling emerging large-scale applications. Microwave plasma decomposition of organic precursors, hydrocarbons, and alcohols, forms a hightemperature environment, where the process of catalyst-free dehydrogenation and consequent formation $\mathrm{C}$ atoms and $\mathrm{C}_{2}$ molecules leads to the nucleation and growth of high-quality few-layer graphene nanosheets. Structure of the synthesized carbon material changed from graphitic nanoparticles to graphene nanosheets with increasing $\mathrm{H} / \mathrm{C}$ atomic ratio in the precursors, for $\mathrm{C}_{2} \mathrm{H}_{2}$ and $\mathrm{CH}_{4}$, respectively. Using alcohols, ethanol $\mathrm{C}_{2} \mathrm{H}_{5} \mathrm{OH}$ and diethylether $-\left(\mathrm{C}_{2} \mathrm{H}_{5}\right)_{2} \mathrm{O}$, the main hydrocarbon fragments generated during the decomposition of $\mathrm{C}_{\mathrm{x}} \mathrm{H}_{\mathrm{y}} \mathrm{O}$ structure resulted in the gas composition with high enough $\mathrm{H} / \mathrm{C}$ atomic ratio to growth nanosheets with low intensity Raman D band and high integrated intensity ratio of 2D/G Raman band, 1.5 and higher. However, the yield of the synthesis strongly depended on the arrangement of atoms in the precursor molecule. Prepared material was analyzed by electron microscopy, Raman and X-ray photoelectron spectroscopy and thermogravimetry. High temperature oxidation resistance and electrical conductivity of prepared samples was investigated.
\end{abstract}

Keywords: Graphene, microwave plasma, growth mechanism

\section{INTRODUCTION}

Gas-phase synthesis of graphene represents a simple, environmentally friendly, and easily scalable production method [1] enabling deployment of carbon nanomaterials in the wide range of emerging large-scale applications such as energy storage, internet-of-things sensors and flexible electronics [2].

Gas-phase growth of graphene from hydrocarbon and alcohol precursors proceeds through consecutive dehydrogenation reactions forming carbon gas composed from $\mathrm{C}$ atoms and $\mathrm{C}_{2}$ molecules which condensate into graphene nuclei in the supersaturation conditions. However, this synthesis process is realized only at a high-enough temperature environment, above $4500 \mathrm{~K}$, and some of the gas-products stay in the form of simple hydrocarbons $\left(\mathrm{CH}_{4}, \mathrm{C}_{2} \mathrm{H}_{2}, \mathrm{C}_{2} \mathrm{H}_{4}\right.$ etc.) $[3,4]$. Depending on the plasma source and stability of the environment [5], the precursor can be partially decomposed by a so-called low temperature channel, where higher hydrocarbons and aromatic compounds containing large amounts of hydrogen are produced [6].

Such reactions can also produce solid state material in the form of soot - carbon black. Frenklach and Wang [7] suggested so called hydrogen abstraction acetylene addition (HACA) mechanism, where benzene molecule, formed by conversion from acetylene, further grows into more complex aromatic molecules, such as naphthalene, by addition of another acetylene molecule. As proposed in the HACA mechanism, the addition of acetylene is followed by consecutive hydrogen abstraction, which removes the $\mathrm{H}$ atoms during the growth phase from the graphene scaffold, leaving the lattice composed of carbon atoms. In case of alcohol based precursors, the presence of oxygen modifies the reaction pathway leading to the formation of $\mathrm{C}$ atoms and $\mathrm{C}_{2}$ 
molecules from hydrocarbon based products of initial decomposition reaction while the other part of the precursor, containing oxygen atom, is converted into $\mathrm{CO}$ or $\mathrm{CO}_{2}$ byproduct depending on the high or low temperature channel of the reaction pathway [4].

In this work we study the growth of graphene nanosheets from precursors with different $\mathrm{H} / \mathrm{C}$ ratio at atmospheric pressure microwave plasma torch and investigate the high temperature oxidation resistance and electrical conductivity of such prepared material.

\section{EXPERIMENTAL}

Graphene nanosheets were synthesized by decomposition of hydrocarbons (methane $\mathrm{CH}_{4}$, acetylene $\mathrm{C}_{2} \mathrm{H}_{2}$ (19 - $38 \mathrm{sccm})$ ) or alcohols (ethanol $\mathrm{C}_{2} \mathrm{H}_{5} \mathrm{OH}\left(99.8 \%\right.$ p.a. Penta), diethylether $\left(\mathrm{C}_{2} \mathrm{H}_{5}\right)_{2} \mathrm{O}$ (99\% p.a. Penta) $(10$ - $100 \mathrm{sccm}$ )) mixed with argon carrier gas using a dual-channel microwave plasma torch at atmospheric pressure. The discharge was ignited in a reactor chamber formed by a quartz tube $(8 \mathrm{~cm}$ in diameter and 20 $\mathrm{cm}$ length enclosed by aluminium flanges) in argon working gas, $Q_{\operatorname{ArC}}=500 \mathrm{sccm}$, flowing through the stainless-steel nozzle central channel, $0.8 \mathrm{~mm}$ diameter (Figure 1), applying microwave power of $270 \mathrm{~W}$. The secondary channel (annulus with outer radius $8.4 \mathrm{~mm}$ and inner radius $7.7 \mathrm{~mm}$ ) was used for the introduction of carbon precursor and argon carrier gas (QArS - $100-700 \mathrm{sccm}$ ). The deposition time was 5 - 10 minutes and the synthesized nanopowder was scraped by brush from the reactor walls after cooling down in argon. More details about the experimental procedure can be found in our recent publications $[5,8]$.
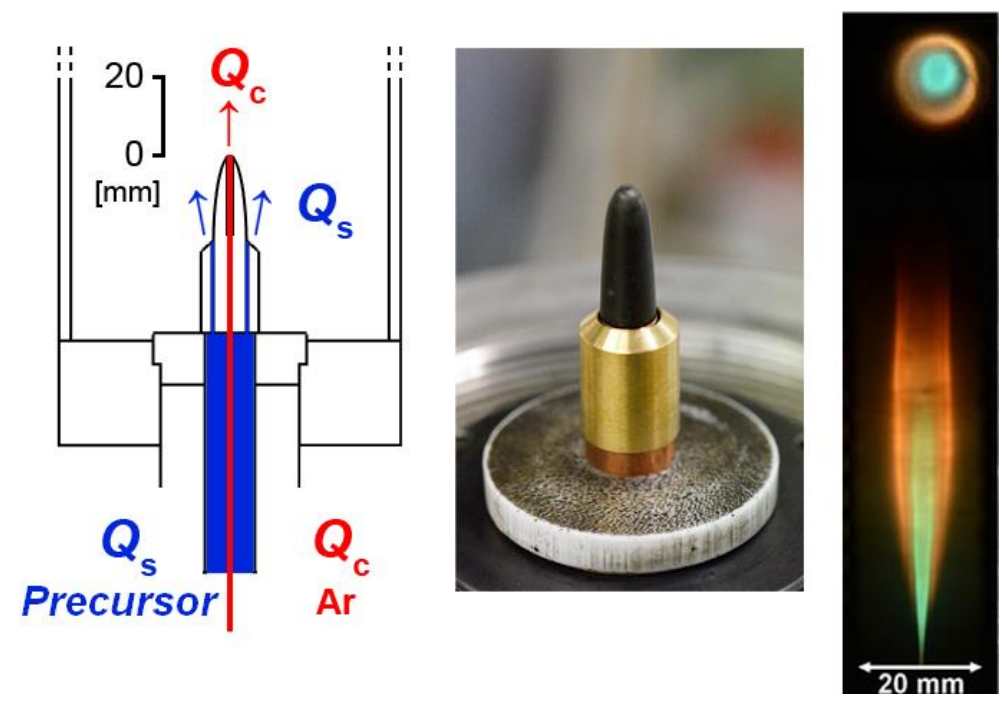

Figure 1 Detail of dual-channel nozzle scheme (left) and its photograph (center). Photograph of the microwave plasma torch discharge in argon with ethanol admixture (right), including top view.

Samples were imaged with MIRA3 (Tescan, Czech Republic) scanning electron microscope (SEM) with Schottky field emission electron gun and equipped with a secondary electron (SE) and back-scattered electron (BSE) detectors as well as Oxford Instruments EDX analyzer (Oxford, England). XPS analysis was performed using a Kratos Analytical Axis Supra (KRATOS-XPS, Kratos Analytical Ltd., UK) spectrometer with a monochromatic Al source using a pass energy of $80 \mathrm{eV}$ for wide spectra and of $20 \mathrm{eV}$ for high-resolution analysis of $\mathrm{C} 1 \mathrm{~s}$ and $\mathrm{O} 1 \mathrm{~s}$ peaks. The analyzed regions were $300 \times 700 \mu \mathrm{m}$ in size. The deconvolution of mentioned peaks was carried out in the CasaXPS 2.3.22PR 1.0 software. Raman spectroscopy was carried out using the HORIBA LabRAM HR Evolution system with $532 \mathrm{~nm}$ laser, using 100x objective, and 5\% ND filter (500 mW maximum power), $600 \mathrm{gr} / \mathrm{mm}$ grating, and $30 \mathrm{~s}$ acquisition time in the range from 500 to 3350 $\mathrm{cm}^{-1}$. 
Thermogravimetric analysis (TGA) was carried out using a Setaram Setsys Evoluton 1750 instrument. The analyses were conducted in a dynamic air atmosphere $\left(20 \mathrm{sccm}^{-1}\right)$ with a constant heating rate of $10^{\circ} \mathrm{C} . \mathrm{min}^{-1}$ in the temperature range from 40 to $1000^{\circ} \mathrm{C}$. The obtained data were processed using the Setaram Processing software. Electrical conductivity of mechanically pressed carbon nanomaterial tablets $(10 \mathrm{~mm}$ in diameter, 10 $\mathrm{mg}$ of nanopowder) were measured by the Ossila 4-probe point system.

\section{GRAPHENE NANOSHEETS SYNTHESIS BY DECOMPOSITION OF HYDROCARBONS}

The decomposition of hydrocarbons by atmospheric pressure microwave discharges leads to formation of a high temperature environment, with gas temperatures above $4500 \mathrm{~K}$. At such conditions, the reaction pathway of the high temperature decomposition of hydrocarbons preferred the dehydrogenation reaction leading to the formation of $\mathrm{C}_{2} \mathrm{H}$ molecules and consequently $\mathrm{C}$ atoms and $\mathrm{C}_{2}$ molecules. However, the equilibrium between $\mathrm{C}_{\mathrm{x}} \mathrm{H}_{\mathrm{y}}$ products and graphene nanosheets nucleation and growth depends on the amount of carbon and hydrogen atoms in the reaction [9].

To study this process, we carried out synthesis using $\mathrm{CH}_{4}(38 \mathrm{sccm})$ and $\mathrm{C}_{2} \mathrm{H}_{2}(19 \mathrm{sccm})$ precursors with different $\mathrm{H} / \mathrm{C}$ ratio, using the same amount of carbon in the deposition mixture. SEM analysis of the samples synthesized under these conditions can be seen in Figure 2a. In the case of $\mathrm{CH}_{4}$, we expect the formation of $\mathrm{C}_{2} \mathrm{H}_{\mathrm{x}}$ molecules and subsequent formation of $\mathrm{C}_{2} \mathrm{H}_{2}$ and $\mathrm{C}_{2}$ molecules leading to the formation of graphene nanosheets. Indeed, we can observe objects with nanosheet structure with lateral dimensions of hundreds of $\mathrm{nm}$ synthesized using the $\mathrm{CH}_{4}$ precursor. Such structures exhibited a low number of defects as determined by Raman spectroscopy analysis (Figure 3a). Low D peak, at $1340 \mathrm{~cm}^{-1}$, intensity was accompanied with high intensity G peak, at $1575 \mathrm{~cm}^{-1}$, and high intensity 2D peak at $2682 \mathrm{~cm}^{-1}$. The full-width half maximum (FWHM) of the 2D peak was $55 \mathrm{~cm}^{-1}$, consistent with a few-layer graphene structure [10]. The integrated intensity ratio of ID/IG and $2 \mathrm{D} / \mathrm{IG}$ was 0.54 and 1.39 , respectively. Low intensity $D^{\prime}, \mathrm{G}^{*}$ and $D+G$ peaks at 1614,2450 and $2928 \mathrm{~cm}^{-1}$, respectively, could be observed as well.

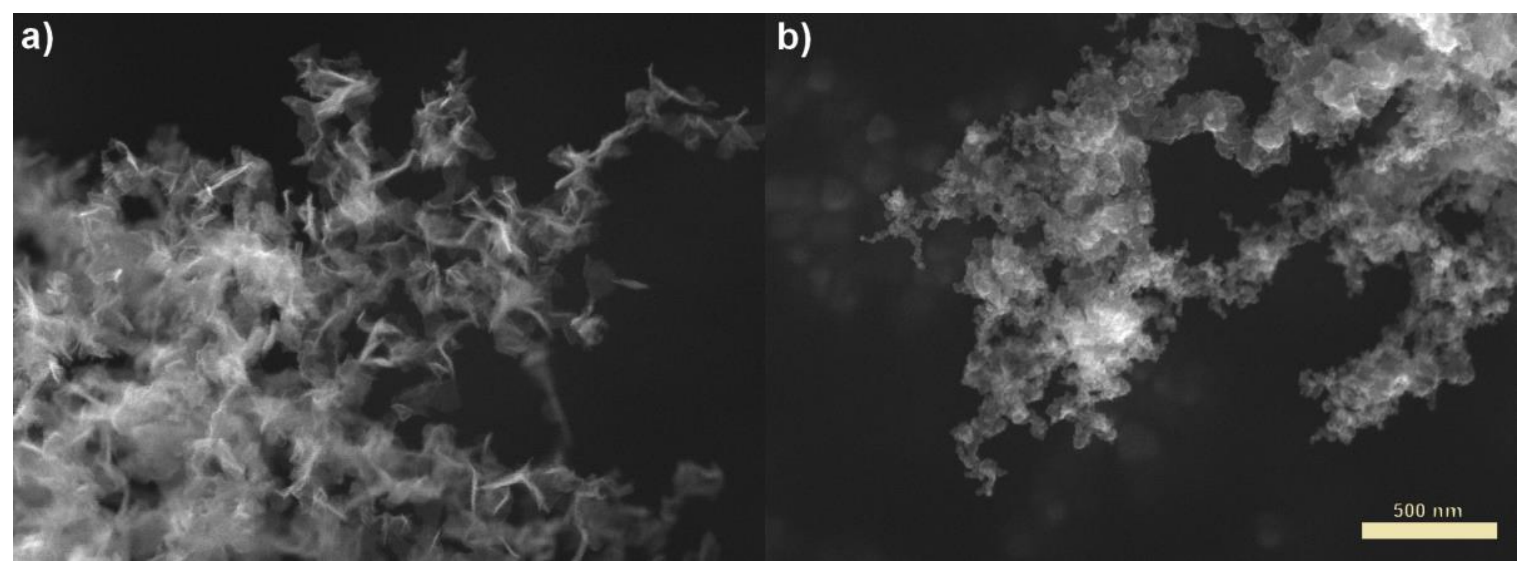

Figure $2 \mathrm{SEM}$ analysis of graphene nanosheets prepared by decomposition of a) $\mathrm{CH}_{4}$ (38 sccm), $\mathrm{H} / \mathrm{C}=0.25$ and b) $\mathrm{C}_{2} \mathrm{H}_{2}(19 \mathrm{sccm}), \mathrm{H} / \mathrm{C}=1$. $Q_{\text {ArC }}=500 \mathrm{sccm}, \mathrm{P}=270 \mathrm{~W}$.

On the other hand, synthesis using acetylene $\left(\mathrm{C}_{2} \mathrm{H}_{2}\right)$ as a precursor led to the formation of spherical carbon nanoparticles (Figure 2b) with diameters ranging from 10 to $100 \mathrm{~nm}$. The high degree of disorder in such a structure resulted in the change of character of its Raman spectra (Figure 3a), where high intensity D peak, at $1336 \mathrm{~cm}^{-1}$, as well $D^{*}, D^{* *}$ and $D^{\prime}$ peaks at 1210,1450 and $1610 \mathrm{~cm}^{-1}$ could be observed. Intensity of the 2D peak was very small in comparison to the $\mathrm{CH}_{4}$ sample. This result was consistent with structures obtained by Choi et al. [11], using high-temperature laser irradiation of acetylene. They suggested that a process like the HACA mechanism or direct decomposition of acetylene into $\mathrm{C}_{2}$ and $\mathrm{H}_{2}$ on the surface of graphene nuclei at high temperatures led to the defect formation and enclosing of the structure. 

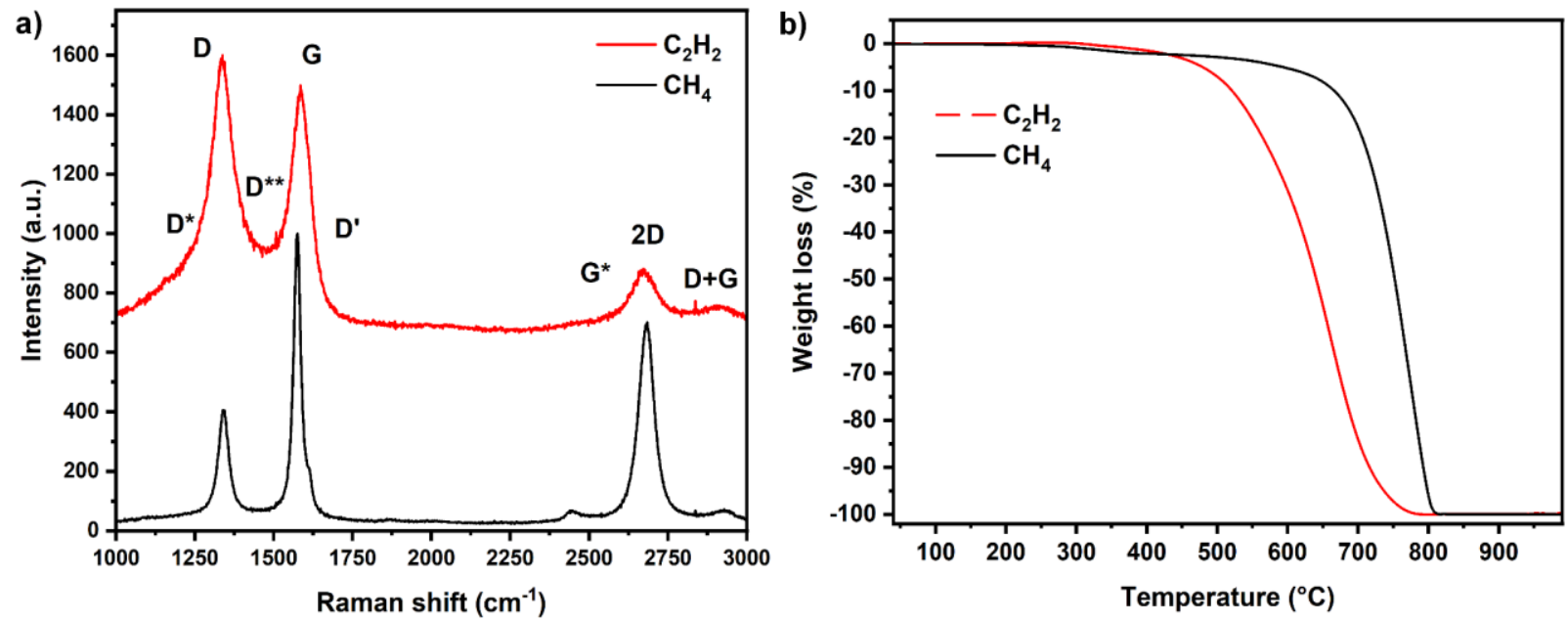

Figure 3 a) Raman spectroscopy and b) TGA of samples prepared by decomposition of $\mathrm{CH}_{4}$ and $\mathrm{C}_{2} \mathrm{H}_{2}$. Q $\mathrm{Q}_{44}$ $=38 \mathrm{sccm}, \mathrm{H} / \mathrm{C}=0.25, \mathrm{Q}_{\mathrm{C} 2 \mathrm{H} 2}=19 \mathrm{sccm}, \mathrm{H} / \mathrm{C}=1, \mathrm{Q}_{\mathrm{ArC}}=500 \mathrm{sccm}, \mathrm{P}=270 \mathrm{~W}$.

As expected, XPS analysis of both samples showed a high content of carbon, over $99 \%$, the rest being oxygen. The presence of oxygen can be explained by a small amount of air impurities in the reaction chamber during the experiment as well as the surface contamination of the sample after being exposed to the air atmosphere. The $\mathrm{sp}^{2} / \mathrm{sp}^{3}$ ratio determined by fitting of $\mathrm{C} 1$ s peak profile was 9.9 and 6.8 for $\mathrm{CH}_{4}$ and $\mathrm{C}_{2} \mathrm{H}_{2}$ samples, respectively.

Amount of disorder in the material substantially influenced its high temperature oxidation resistance measured by TGA as can be seen in Figure 3b. Carbon nanoparticles prepared by decomposition of $\mathrm{C}_{2} \mathrm{H}_{2}$, started to combust, around $500{ }^{\circ} \mathrm{C}$, and the exhibited total weight loss around $780^{\circ} \mathrm{C}$, while the graphene nanosheets prepared from $\mathrm{CH}_{4}$ were stable up to $650^{\circ} \mathrm{C}$ with total weight loss temperature of $815^{\circ} \mathrm{C}$.

\section{GRAPHENE NANOSHEETS SYNTHESIS BY DECOMPOSITION OF ALCOHOLS}

In recent years, the synthesis of graphene nanosheets using high temperature plasma discharges was focused, except for methane, to ethanol as a precursor. Dato and Frenklach [12] suggested that ethanol possessed an ideal $\mathrm{H} / \mathrm{C} / \mathrm{O}$ ratio for graphene nanosheet synthesis. This idea was suggested after successful synthesis of graphene from ethanol and its isomer dimethylether $\mathrm{CH}_{3} \mathrm{OCH}_{3}$. Diethylether structure with two $\mathrm{CH}_{3} \mathrm{CH}_{2}$ groups connected by an oxygen atom represents an extension of the ethanol molecular arrangement $\mathrm{C}_{2} \mathrm{H}_{5} \mathrm{OH}$. However, in this case the ratio between the number of $\mathrm{H}, \mathrm{C}$ and $\mathrm{O}$ atoms changes substantially.

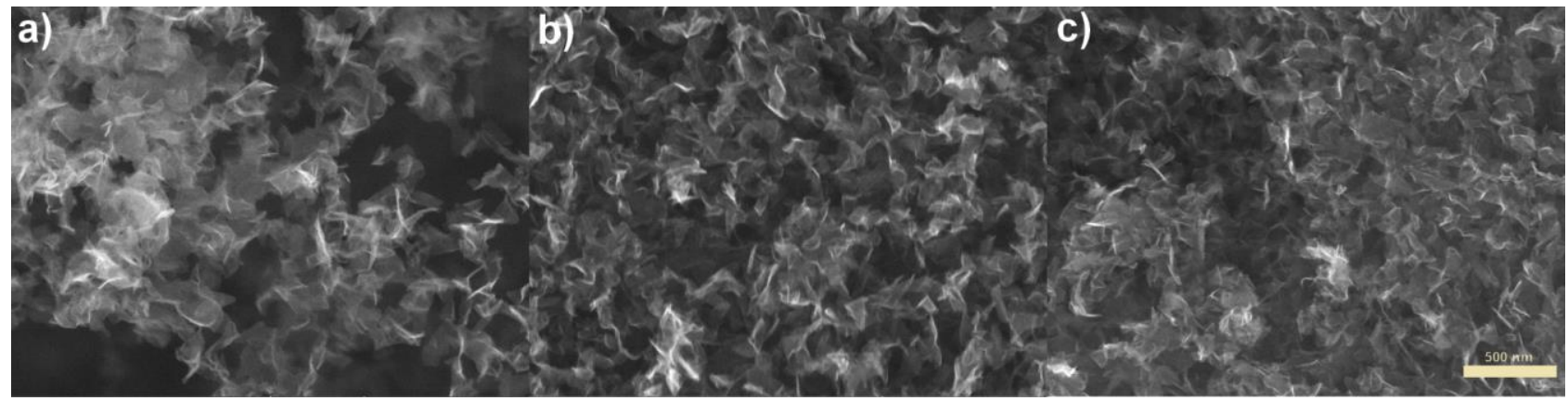

Figure 4 SEM analysis of graphene nanosheets prepared by decomposition of a) ethanol (Qeth $=50 \mathrm{sccm}$ ), $\mathrm{H} / \mathrm{C}=3, \mathrm{~b}$ ) diethylether $+\mathrm{H}_{2}\left(\mathrm{Q}_{\text {diett }} / \mathrm{QH}_{\mathrm{H}}=100 / 50 \mathrm{sccm}\right), \mathrm{H} / \mathrm{C}=2.75$ and c) diethylether $\left(Q_{\text {dieth }}=100 \mathrm{sccm}\right.$ ), $\mathrm{H} / \mathrm{C}=2.5$. $\mathrm{QArC}_{\mathrm{A}}=500 \mathrm{sccm}, \mathrm{P}=270 \mathrm{~W}$. 
We carried out synthesis using $\left(\mathrm{C}_{2} \mathrm{H}_{5}\right)_{2} \mathrm{O}$ with and without $\mathrm{H}_{2}$ admixture to investigate the influence of various $\mathrm{H} / \mathrm{C}$ atomic ratio on the synthesis process and compared the results with material prepared using ethanol.

As can be seen on SEM micrographs in Figure 4, the synthesis of graphene nanosheets was successful using all precursors. Raman spectroscopy analysis of prepared structures can be seen in Figure 5a. All samples exhibited a low amount of structural disorder, ID/IG Raman band ratio $0.5-0.6$, and high ratio of I2D/IG, of Raman bands, $1.6-1.7$, leading to the conclusion that the structural properties did not change even with change of $\mathrm{H} / \mathrm{C}$ ratio from 3 to 2.5 . Also, the change of $\mathrm{O} / \mathrm{C}$ ratio from 0.5 to 0.25 did not influence the quality of prepared nanostructures. Therefore, the conversion of part of the precursor molecule into $\mathrm{CO}$ during the synthesis had no effect on the quality of the material. Additional hydrogen had negligible influence on the synthesis process. At the same time, we could observe around 4 times lower yield of the synthesis, by weighting the produced nanopowder, using diethylether precursor. This result suggests precursor molecular arrangement plays an important role in the efficiency of the synthesis process.
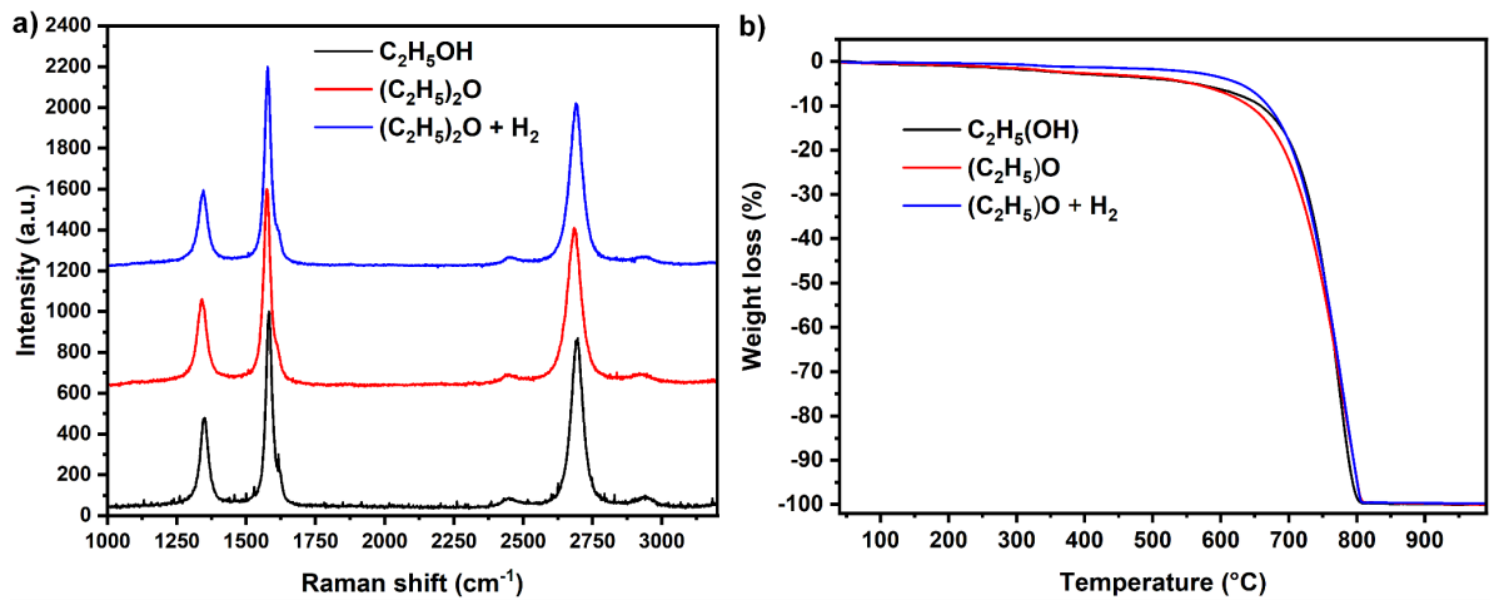

Figure 5 a) Raman spectroscopy and b) TGA of samples prepared by decomposition of ethanol and diethylether precursors. Qeth $=50 \mathrm{sccm}, Q_{\text {dieth }}=100 \mathrm{sccm}, Q_{\mathrm{H} 2}=50 \mathrm{sccm}, Q_{\text {ArC }}=500 \mathrm{sccm}, \mathrm{P}=270 \mathrm{~W}$.

XPS analysis of all samples showed similarly to samples prepared from hydrocarbons a high, but slightly lower content of carbon, over $98 \%$, the rest being oxygen. The $\mathrm{sp}^{2} / \mathrm{sp}^{3}$ ratio determined by fitting $\mathrm{C} 1 \mathrm{~s}$ peak profile was 19 and 21 for $\mathrm{C}_{2} \mathrm{H}_{5} \mathrm{OH}$ and $\left(\mathrm{C}_{2} \mathrm{H}_{5}\right)_{2} \mathrm{O}$ samples, respectively.

Given the low amount of disorder and high $\mathrm{sp}^{2 /} \mathrm{sp}^{3}$ ratio of all the samples prepared by decomposition of alcohol precursors exhibited excellent oxidation resistance as can be seen in Figure $\mathbf{5 b}$. The measured TG curves in air had almost identical profiles with total mass loss around $810{ }^{\circ} \mathrm{C}$, like the $\mathrm{CH}_{4}$ sample, and in good agreement with our previously published study [8].

\section{MEASUREMENT OF ELECTRICAL CONDUCTIVITY OF GRAPHENE NANOPOWDER TABLETS}

From an application point of view the good thermal stability under oxidation atmosphere combined with a good electrical conductivity can be of an advantage. Different carbon nanomaterials create conductive pathways depending on their geometry and a form of layers created from them. To minimize such an effect, we measured conductivity of tablets with the same diameter formed from the same amount of nanopowder (Table 1). As we can see, all the graphene nanosheet samples showed similar value of conductivity $\sim 1000 \mathrm{~S} . \mathrm{m}^{-1}$, while the conductivity of the tablet formed from carbon nanoparticles synthesized using $\mathrm{C}_{2} \mathrm{H}_{2}$ precursor was much lower $60 \mathrm{~S} \cdot \mathrm{m}^{-1}$. The electrical conductivity was higher for samples with a lower amount of disorder in the material, lower ID/IG ratio, but this comparison was not valid for thermally expanded graphite. This sample exhibited a high ID/G ratio, but the conductivity was comparable to graphene nanosheets. This can be caused by sample 
structure, nanoflakes of pure graphite, which exhibit very high conductivity and form a very good conductive path.

Table 1 Electrical conductivity of carbon nanomaterial pellets prepared by decomposition of various carbon precursors. Conductivity measurement uncertainty $\pm 4 \%$.

\begin{tabular}{|c|c|c|c|c|c|c|}
\hline Precursor & $\mathrm{CH}_{4}$ & $\mathrm{C}_{2} \mathrm{H}_{2}$ & $\mathrm{C}_{2} \mathrm{H}_{5} \mathrm{OH}$ & $\left(\mathrm{C}_{2} \mathrm{H}_{5}\right)_{2} \mathrm{O}$ & $\left(\mathrm{C}_{2} \mathrm{H}_{5}\right)_{2} \mathrm{O}+\mathrm{H}_{2}$ & expanded graphite \\
\hline Conductivity $\left(\mathrm{S} . \mathrm{m}^{-1}\right)$ & 980 & 60 & 1140 & 1090 & 1150 & 1180 \\
\hline Raman ID/IG ratio & 0.54 & 1.60 & 0.54 & 0.61 & 0.54 & 2.48 \\
\hline
\end{tabular}

\section{CONCLUSIONS}

We investigated the synthesis of graphene nanosheets using microwave plasma torch at atmospheric pressure by decomposition of hydrocarbon and alcohol precursors with various $\mathrm{H} / \mathrm{C} / \mathrm{O}$ composition ratio. We showed that the use of all precursors with $\mathrm{H} / \mathrm{C}$ ratio higher than 2, led to the synthesis of graphene nanosheets with low ID/IG and high I2D/IG Raman band integrated intensity ratio and that presence of the oxygen did not substantially influence the nanosheet's structure. However, the arrangement of atoms of the precursor molecule influenced the decomposition reaction pathway and consequently the yield of the synthesis. This result was consistent with the dehydrogenation reaction growth mechanism of graphene nanosheets. Higher quality material exhibited substantially higher electrical conductivity and high temperature oxidation resistance.

\section{ACKNOWLEDGEMENTS}

This work was supported by The Czech Science Foundation under project 18-08520S and in part by project LM2018097 funded by the Ministry of Education, Youth and Sports of the Czech Republic. CzechNanoLab project LM2018110 funded by MEYS CR is gratefully acknowledged for the financial support of the XPS measurements by David Pavliňák at CEITEC Nano Research Infrastructure.

\section{REFERENCES}

[1] DATO, A. Graphene synthesized in atmospheric plasmas-A review. J. Mater. Res. 2019, vol. 34, no. 1, pp. 214230.

[2] YANG,J., HU, P. and YU, G. Perspective of graphene-based electronic devices: Graphene synthesis and diverse applications. APL Mater. 2019, vol. 7, no. 2, p. 020901.

[3] SHAVELKINA, M. B., FILIMONOVA, E. A. and AMIROV, R. K. Effect of helium/propane-butane atmosphere on the synthesis of graphene in plasma jet system. Plasma Sources Sci. Technol. 2020, vol. 29, no. 2, p. 025024.

[4] RINCON, R. et al. Experimental research on ethanol-chemistry decomposition routes in a microwave plasma torch for hydrogen production. Chem. Eng. J. 2016, vol. 284, pp. 1117-1126.

[5] TOMAN, J., JASEK, O., SNIRER, M., KUDRLE, V., and JURMANOVA, J. On the interplay between plasma discharge instability and formation of free-standing graphene nanosheets in a dual-channel microwave plasma torch at atmospheric pressure. Journal of Physics D: Applied Physics. 2019, vol. 52, no. 26. p. 265205.

[6] HARRIS, S. J. and WEINER, A. M. Chemical kinetics of soot particle growth. Annu. Rev. Phys. Chem. 1985, vol. 36, no. 1, pp. 31-52.

[7] FRENKLACH, M. and WANG, H. Detailed modeling of soot particle nucleation and growth. Symp. Combust. 1991, vol. 23, no. 1, pp. 1559-1566.

[8] JAŠEK, O. et al. Controlled high temperature stability of microwave plasma synthesized graphene nanosheets. J. Phys. D Appl. Phys. 2021, vol. 54, no. 16, p. 165201.

[9] TSYGANOV, D.et al. On the plasma-based growth of 'flowing' graphene sheets at atmospheric pressure conditions. Plasma Sources Sci. Technol. 2016, vol. 25, no. 1, p. 015013. 
[10] FERRARI, A. C. et al. Raman spectrum of graphene and graphene layers. Phys. Rev. Lett. 2006, vol. 97, no. 18, p. 187401.

[11] $\mathrm{CHOI}, \mathrm{M}$. et al. Formation of shell-shaped carbon nanoparticles above a critical laser power in irradiated acetylene. Adv. Mater. 2004, vol. 16, no. 19, pp. 1721-1725.

[12] DATO, A. and FRENKLACH, M. Substrate-free microwave synthesis of graphene: experimental conditions and hydrocarbon precursors. New J. Phys. 2010, vol. 12, no. 12, p. 125013. 